\title{
Novel reverse osmosis desalination of sea water
}

\author{
D. F. Dyer \& J. S. Ragan \\ Department of Mechanical Engineering, Auburn University, USA
}

\begin{abstract}
One requirement of sustainable irrigation is a guaranteed source of water at adequate levels. It is also obvious that the cost of the irrigation water delivered to the user must allow the user to profit from its use. The costs of irrigation falls typically in three categories: 1 . Cost of the water used; 2 . Energy cost to purify and transport the water; and 3. Initial costs of the infrastructure and its maintenance. This paper addresses all of these requirements for sustainable irrigation. It is proposed that the ocean is the ultimate source of sustainable water. Further the required purification of the water is to be accomplished by a novel reverse osmosis system which minimizes the energy costs. Finally, a solar collection system is incorporated in the proposed system to minimize the impact of global warming due to use of fossil fuels. The proposed system has particular application to desert areas near oceans such as North Africa and Australia. This paper includes the development of a model for performance and cost of the system and shows the circumstances for which the proposed system is viable.
\end{abstract}

Keywords: reverse osmosis, desalination, OTEC, sustainable irrigation.

\section{Introduction}

This paper explores a new concept for producing desalinated water from the ocean by a combination of a novel reverse osmosis (RO) system for desalination of sea water with an ocean thermal energy cycle (OTEC). In this paper a brief summary of conventional state-of-the-art RO desalination and OTEC will be given. In the following section a description of the proposed, unconventional RO system with its advantages will be given. The next section will show how a closed OTEC system can be used to provide the power requirements for the unconventional RO system and will include the further advantages of the combined unconventional RO system/OTEC system. A final section will provide 
an analysis determining the pump and energy recovery capacity as well as required input power for three systems: 1 . Conventional RO; 2 . Unconventional RO; and 3. Unconventional RO coupled with an OTEC system.

\subsection{Conventional OTEC system}

Many recent excellent papers describe the state of art in OTEC (e.g. [1-3]). Briefly, there are two types of OTEC systems: closed and open. In a closed system (see Figure 1), a closed loop using a working fluid such as ammonia incorporates an evaporator heat exchanger to transfer heat from warm surface ocean water to the ammonia. The vaporized ammonia is expanded through a turbine to produce power. The exhaust from the turbine is then condensed with cooler water from deep within the ocean in a condensing heat exchanger. Finally, the liquid ammonia from the condenser is pumped back to the evaporator to repeat the cycle.

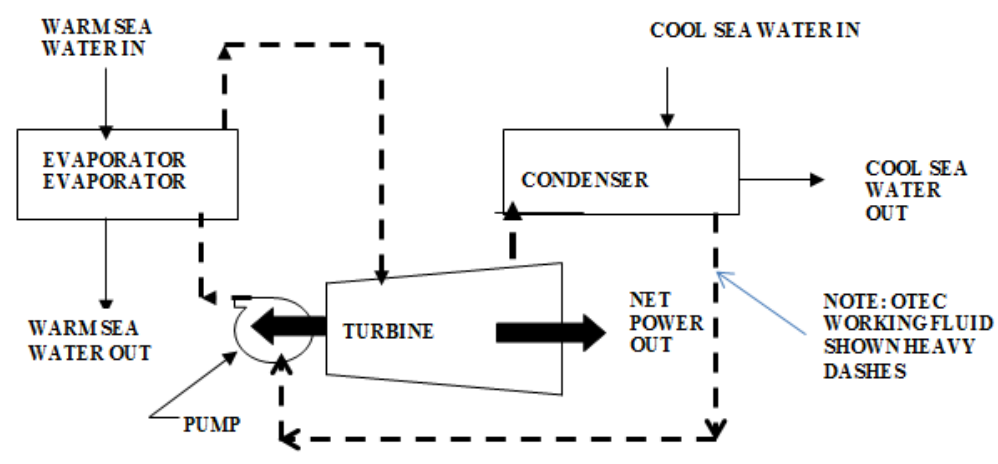

Figure 1: $\quad$ Conventional closed OTEC system.

In an open cycle OTEC system (see Figure 2), a vacuum is pulled on a volume of warm ocean water from the top surface of the ocean causing the water to flash to steam. The steam is then expanded through a turbine to produce power. The turbine exhaust is then condensed in a heat exchanger using cool water from deep in the ocean. This condensed water is desalinated and can be used for irrigation purposes. In the author's opinion, the open cycle will never be competitive with the closed cycle because the vapor volume at the turbine inlet is so large that it would not be economically practical, and even worse, the exhaust volume is larger and would require a very large condensing heat exchanger. As a result it is not practical to envision the use of an open OTEC cycle to obtain significant amounts of irrigation water.

With a $20 \mathrm{C}$ temperature difference, the maximum possible OTEC thermal efficiency is about 7\% [3]. Systems in operation today are typically $2 \%$ efficient [3]. With the incorporation of energy recovery systems as shown in Figure 1, it is 


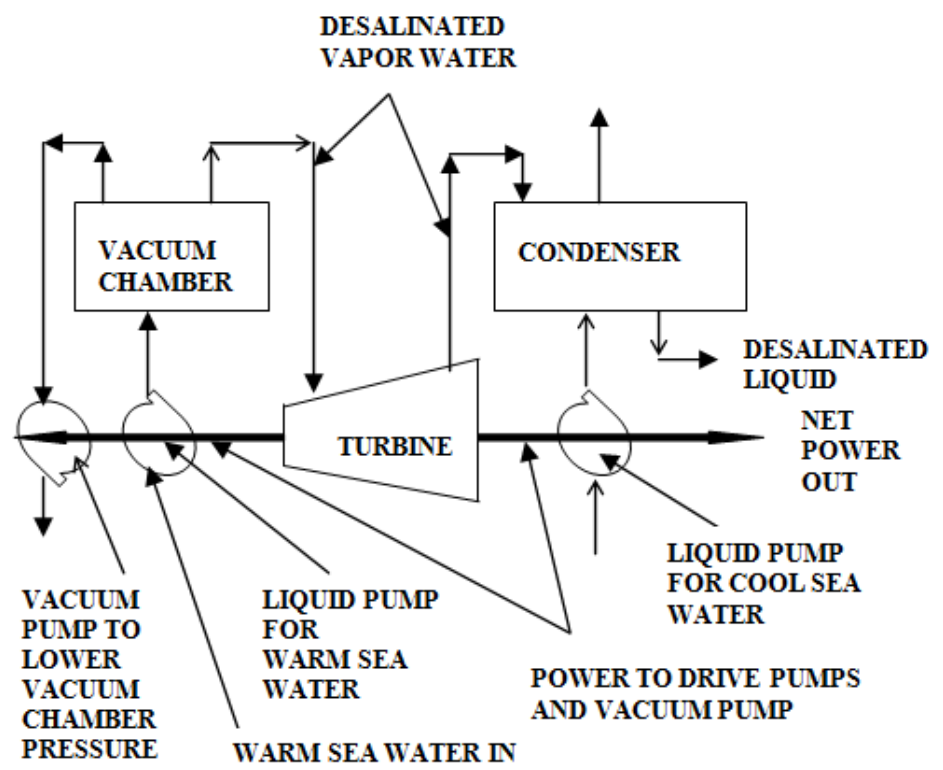

Figure 2: $\quad$ Open OTEC system schematic.

possible to achieve closer to the theoretical maximum efficiency [4]. However, the literature does not predict an exact target value. The authors' analysis indicates that efficiency between 4 and $5 \%$ is attainable for the application described below.

\section{Conventional Reverse Osmosis (RO) system}

Numerous papers (e.g. [5-7]) review the current state of art for RO systems. A conventional RO system is shown schematically in Figure 3. In this system, sea water from near the ocean surface is drawn via an electric driven pump into a pretreatment phase depending on the particular contamination present. The pressure leaving the pump must equal the osmotic pressure of sea water plus the pressure drop required across the filter/piping/etc. As an example the osmotic pressure might be 40 atmospheres and the pressure drop across the filter would be 30 atmospheres requiring a pump outlet pressure of approximately 70 atmospheres. Some water passes through the filter and most of the dissolved solids are removed rendering the water stream suitable for irrigation. More pump power is delivered to the waste stream than the desalinated water stream. In order to capture some of the energy in the waste stream, an energy recovery device (ERD) is incorporated as shown to provide some of the pump power. Reference [8] gives an excellent summary of ERD. A high efficiency ERD can capture 


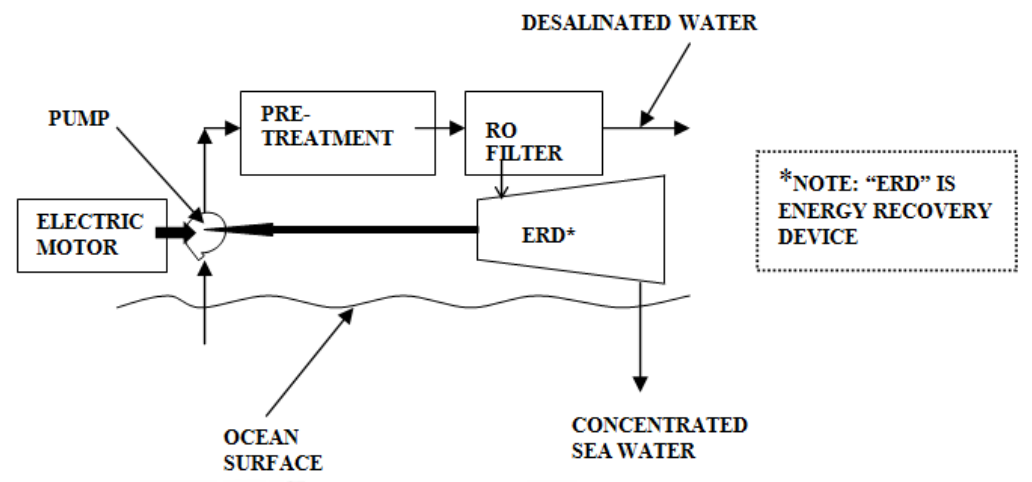

Figure 3: $\quad$ Conventional RO system.

around $80 \%$ of the energy in the concentrated sea water stream. A big factor in the pump power required is the necessity to pump the water to typically double the osmotic pressure. The improved RO system described in the next section dramatically reduces pumping power. A typical power requirement is more than $2 \mathrm{kwh} /$ cubic meter of desalinated water [7,9] for a modern conventional RO system with energy recovery in which the recovery rate for desalinated water is $45 \%$. This figure is for the main pumping power which ranges from 65 to $85 \%$ of the total power to run system [9]. The major auxiliary pumping requirements are to provide the intake pumping power (typically 15 to $20 \%$ of the total power) and the power for pre-filtration (typically $10 \%$ of total power) [10]. The minimum energy required is about $1 \mathrm{kwh} /$ cubic meter [7] again depending on the salinity and water recovery rate.

\section{Unconventional RO system}

An unconventional RO system is shown in Figure 4. The significant difference between this system and a conventional RO system is that the entire system is located deep in the ocean. The system would be packaged in one or more sealed vessels and either supported by the ocean floor or suspended by a cable from a platform. The entire package could be lifted to surface by a tether for maintenance purposes. A pipe (probably flexible so that it could be reeled up) to provide desalinated water from the unit to the surface is provided as shown in Figure 4. The pump is located downstream of the RO filter and is used to control the permeate pressure by providing enough pressure to move permeate to shore. Initially the desalinated water line must be "primed" with fresh water. The hydrostatic head imposed by the ocean provides the necessary feed pressure to initiate the process. 


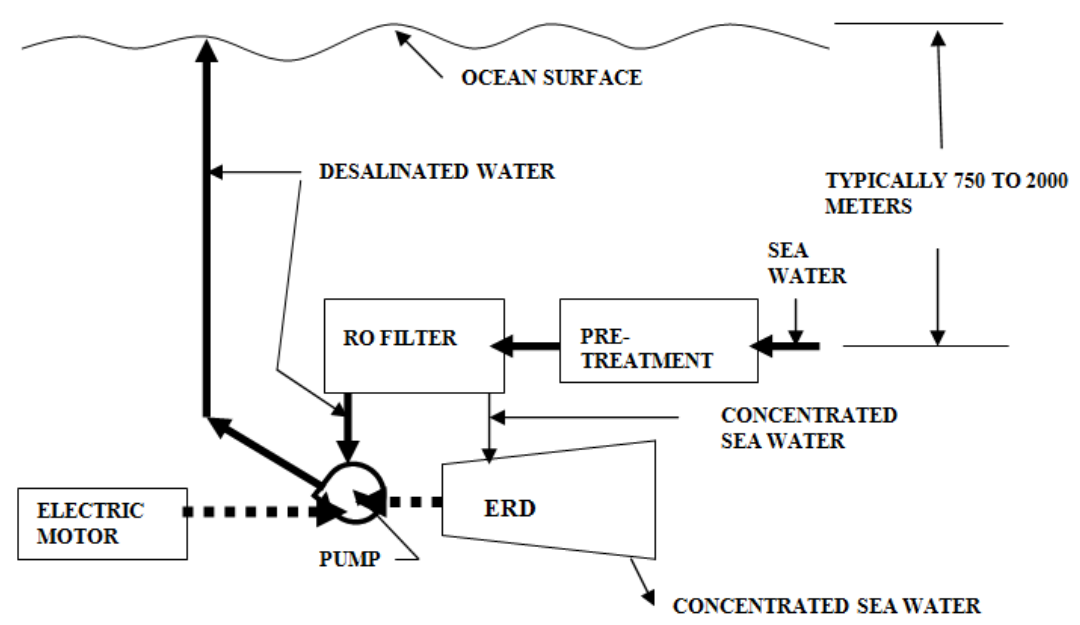

Figure 4: Unconventional RO system.

The advantages of this system as compared to a conventional RO system are numerous. These advantages include:

1. Since the pressure due to hydrostatic head of the ocean at the pump inlet can be greater than the osmotic pressure, the required outlet pump pressure is dramatically reduced. As a result the pumping power and pump/prime mover size is much lower.

2. Since the energy per unit mass in the waste stream is reduced due to the hydrostatic head of the ocean, the size of the ERD and its cost is decreased and its efficiency may be increased. As a result the amount of prime mover power that must be utilized to drive the pump is decreased since a higher percentage of energy will be available from the waste stream ERD. The waste concentrated sea water stream can be discharged directly from the turbine reducing piping and pumping costs as compared to the conventional RO system.

3. The hydrostatic head imposed by the desalinated water leaving the RO filter is less than the hydrostatic head of the ocean water, providing more than enough pressure drop to overcome friction in the desalinated water piping and pressure drop across the filter.

4. The salinity of ocean water is typically less as the depth of submersion increases. This decreases the required osmotic pressure which will give even a greater desalinated water to waste water ratio and/or reduced pumping power.

5. The system is not subject to destruction by hurricanes, cyclones or tsunamis. 


\section{Unconventional RO system powered by a closed OTEC cycle}

An unconventional RO system powered by a closed OTEC cycle is shown schematically in Figure 5.

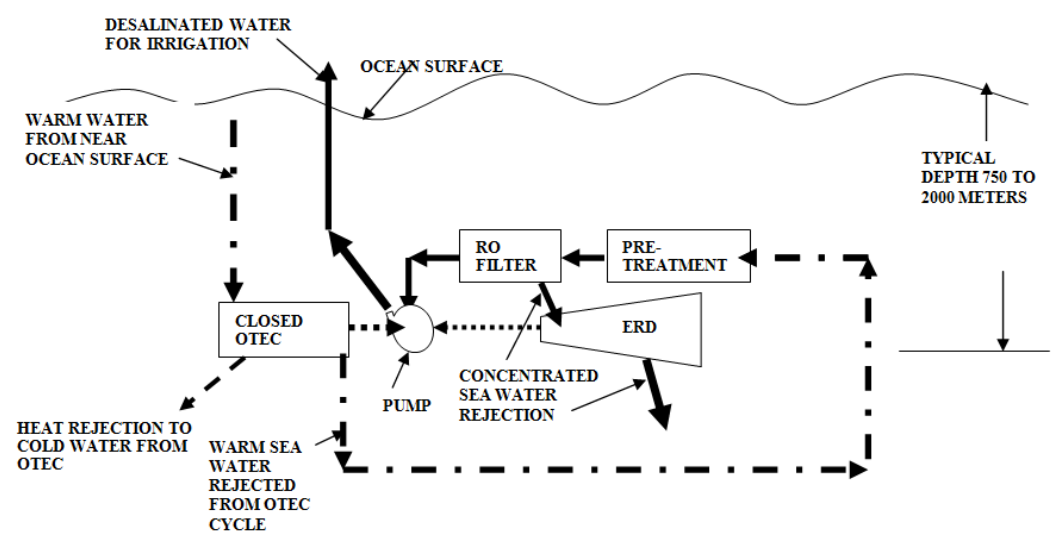

Figure 5: $\quad$ Unconventional RO system powered by a closed OTEC cycle.

In the cycle shown in Figure 5, the closed OTEC system replaces an electric motor. The warm water used to drive the closed OTEC system is subsequently pre-treated and processed by an RO filter in the unconventional RO system. In this configuration, the OTEC system is also unconventional in that it has been placed deep within the ocean (an idea not heretofore disclosed). This configuration allows the production of desalinated water without any purchased power! Hence, the system shown operates in a completely renewable fashion. Obviously, the one major disadvantage on this system is the added cost and maintenance of the OTEC system. However, there are several major advantages of operating the unconventional system shown in Figure 5 even compared to an unconventional RO system powered by an electric motor as shown in Figure 4. These advantages include:

1. There is no need to run expensive power cables. Since no electricity is required the system would be practical in many locations such as islands and expansive dry to desert areas were an electrical power infrastructure does not exist.

2. Although a pipe (flexible) must be added to provide warm water to the OTEC, no piping is required for heat rejection from the OTEC system because the OTEC is submerged in cold water allowing the heat to be rejected directly from the OTEC engine.

3. A major advantage is that no pumping power must be expended to provide heating and cooling water to the OTEC system since heat rejection is direct and the heat addition is provided by the pump 
power used to deliver desalinated water from the RO unit. (There would be some minor pump power required to overcome fluid friction in the pipe supplying warm water to the OTEC unit but this loss is supplied by the head pressure difference between ocean and desalinated water. The elimination of this pumping requirement will substantially improve the efficiency of the OTEC system making it a more practical application.

4. The cost of equipment for converting shaft power from the OTEC system to electric power and then back to shaft power for the RO system is eliminated since the OTEC system can be used to drive the RO system pump directly. In addition, there is at least a $10 \%$ loss in energy in converting shaft power via a generator to electricity and then converting electrical power to shaft power via an electric motor.

\section{Conclusions}

This section provides a thermodynamic analysis of each of the three systems described above and develops pertinent data for the performance of these systems. This data is based on current state of art of conventional RO systems. The results are provided in a table and conclusions are then drawn from these results. To begin the analysis the efficiency of the electric drive motor and pumps is required as inputs. Let the efficiency of the electric motor be $\eta_{\text {motor }}$ and the efficiency of the pump be $\mathrm{n}_{\text {pump. The }}$ efficiency of the pump/motor combination is given by:

$$
\eta_{\text {overall }}=\eta_{\text {motor }} \times \mathrm{n}_{\text {pump }}
$$

The column of fresh water leaving the RO unit weighs less than the seawater. A typical weight density difference is $2.6 \%$. The head at any depth is the weight density multiplied by the depth. Hence, the difference in head between fresh and ocean water at any depth, $\mathrm{h}$, is

$$
\text { Difference in head }=.026 \times \mathrm{h} \times \text { weight density of fresh water }
$$

It is desirable to determine the power consumption based on a unit production of fresh water, $m_{\text {base }}=1 \mathrm{~m}^{3} /$ day. The total input of water provided by the main pump for this base flow, $\mathrm{m}_{\text {total }}$, can be determined from a mass balance for a given fraction of fresh water to input water which is called the recovery rate, $R$. This balance gives

$$
\mathrm{m}_{\text {total }}=\mathrm{m}_{\text {base }} / \mathrm{R}
$$

Ideal pump power is the product of the volume of water flow with the pressure rise across the pump. The actual power input is the ideal power input divided by the pump efficiency. The total power supplied to the motor is the 
actual pump power divided by the motor efficiency. Hence, the ideal pump power divided by the product of the pump and motor efficiency, i.e.

Total power to electric motor driving pump $=\mathrm{m}_{\text {total }} \times \Delta \mathrm{P} /\left(\rho \times \eta_{\text {overall }}\right)$

Where $\rho$ is density of fluid into pump, and $\Delta \mathrm{P}$ is the pressure rise across the pump. The specific pump power can be obtained by replacing $\mathrm{m}_{\text {total }}$ by $\mathrm{m}_{\text {base }} / \mathrm{R}$ in equation (4) and dividing through by $\mathrm{m}_{\text {base }}$ to give the pump specific power

$$
\mathrm{W}_{\mathrm{S}}=\text { Pump Power } / \mathrm{m}_{\text {base }}=\Delta \mathrm{P} /\left(\rho \times \eta_{\text {overall }}\right)
$$

For the conventional RO system the main pump is upstream of the filter while for the unconventional system the pumps are downstream of the filter. The conventional RO system also requires a supply pump while the unconventional systems utilize the main pump to also serve the supply function. The total specific power consumption is given by

$$
\mathrm{W}_{\mathrm{S}, \text { total }}=\mathrm{W}_{\mathrm{S} \text {,main }}+\mathrm{W}_{\mathrm{S}, \text { supply }}
$$

where the subscripts main and supply refer to the main and supply pump respectively. In an unconventional system an energy recovery device (ERD) is required. The capacity of the ERD is the energy in the waste stream which is the product of with the waste stream volume with the pump outlet pressure. If one lets $m_{\text {base }}$ in equation (3) equal the actual production of fresh water, $m_{\text {total }}$ is the actual total water flow rate into the main pump. Equation (3) can then be arranged to give

$$
\mathrm{m}_{\text {waste }}=\mathrm{m}_{\text {total }}-\mathrm{m}_{\text {base }}=\left(\mathrm{m}_{\text {base }} / \rho\right)[(1-\mathrm{R}) / \mathrm{R}]
$$

Replacing $\dot{m}_{\text {total }}$ in equation (4) by $\dot{m}_{\text {waste }}$ from equation (7) gives

$$
\text { Capacity of } \mathrm{ERD}=\left(\mathrm{m}_{\text {waste }} / \rho\right)[(1-\mathrm{R}) / \mathrm{R}] \mathrm{x} \Delta \mathrm{P}
$$

The total pump capacity is the product of the total specific pump capacity with the total flow of fresh water.

$$
\text { Total Pump Capacity }=\mathrm{W}_{\mathrm{S}, \text { total }} \times \mathrm{m}_{\text {total }}
$$

The total power input to the pumps is the total pump capacity from equation (9) divided by the pump efficiency, i.e.

$$
\text { Total Pump Capacity }=\mathrm{W}_{\mathrm{S} \text {,total }} \times \mathrm{m}_{\text {total }} / \eta_{\text {pump }}
$$

The main and supply pumps for a conventional RO system are essentially at sea level. For the unconventional system the RO filter must be at a depth such that it is at osmotic pressure on the inlet side. Since the head is the weight density multiplied by depth, the

$$
\text { Required depth }=\text { Osmotic Pressure/ weight density of sea water }
$$

Operating conditions for the most advance conventional RO system [11] were used in conjunction with equations (1) to (11) to determine the performance of an advanced, conventional RO system. The same conditions were then used in 
conjunction with equations ( 1 to 11 ) to determine the performance of an unconventional RO system powered by an electric motor and by an OTEC engine. All these results are given in Table 1.

Table 1: $\quad$ Results of thermodynamic analysis.

\begin{tabular}{|c|c|c|c|c|}
\hline Variable & Units & $\begin{array}{l}\text { State } \\
\text { of art } \\
\text { RO }\end{array}$ & $\begin{array}{l}\text { Proposed RO } \\
\text { system }\end{array}$ & $\begin{array}{c}\text { Proposed } \\
\text { RO system } \\
\text { powered by } \\
\text { OTEC }\end{array}$ \\
\hline $\begin{array}{l}\text { Assumed production of } \\
\text { desalinated water }\end{array}$ & $\mathrm{m}^{3} /$ day & 10,000 & 10,000 & 10,000 \\
\hline Osmotic pressure & bar & 27 & 27 & 27 \\
\hline $\begin{array}{l}\text { Delivery pressure from main } \\
\text { pump }\end{array}$ & bar & 48 & 27 & 27 \\
\hline $\begin{array}{l}\text { Recovery rate-ratio permeate to } \\
\text { feed }\end{array}$ & fraction & 0.45 & 0.45 & 0.45 \\
\hline Efficiency pump & fraction & 0.88 & 0.88 & 0.88 \\
\hline Efficiency motor & fraction & 0.98 & 0.98 & not app* \\
\hline Overall pump/motor efficiency & fraction & 0.862 & 0.862 & 0.880 \\
\hline $\begin{array}{l}\text { Fraction of energy recovered by } \\
\text { ERD }\end{array}$ & fraction & 0.96 & not app* & not app* \\
\hline $\begin{array}{l}\text { Head difference sea water } v \text { s. } \\
\text { fresh water }\end{array}$ & bar & 0 & 0.702 & 0.702 \\
\hline $\begin{array}{l}\text { Design pressure drop for delivery } \\
\text { to shore }\end{array}$ & $\mathrm{bar} / 1000 \mathrm{~m}$ & 0.23 & 0.23 & 0.23 \\
\hline Distance to shore & $\mathrm{m}$ & 1000 & 20000 & 20000 \\
\hline $\begin{array}{l}\text { Total flow rate of desalinated } \\
\text { water for } 1 \mathrm{~m}^{3} / \mathrm{hr} \text { desalinated } \\
\text { water }\end{array}$ & $\mathrm{m}^{3} / \mathrm{hr}$ & 2.222 & 1.000 & 1.000 \\
\hline $\begin{array}{l}\text { Specific energy consumption main } \\
\text { pump }\end{array}$ & $\mathrm{kwh} / \mathrm{m}^{3}$ & 1.866 & 0.845 & 0.828 \\
\hline $\begin{array}{l}\text { specific energy consumption } \\
\text { supply pump (from RO to shore) }\end{array}$ & $\mathrm{kwh} / \mathrm{m}^{3}$ & 0.007 & 0.145 & 0.142 \\
\hline $\begin{array}{l}\text { Total specific energy consumption } \\
\text { main pump+supply pump }\end{array}$ & $\mathrm{kwh} / \mathrm{m}^{3}$ & 1.874 & 0.990 & 0.970 \\
\hline Energy recovery (ERD) capacity & $\mathrm{kw}$ & 286.57 & 0.00 & 0 \\
\hline Total pump capacity & $\mathrm{kw}$ & 777.63 & 352.01 & 344.97 \\
\hline Pump power input & $\mathrm{kw}$ & 883.68 & 400.01 & 392.01 \\
\hline Ocean depth & $\mathrm{m}$ & 0.00 & 300.16 & 300.16 \\
\hline
\end{tabular}


Comparison of the results from Table 1 clearly shows the great advantage of the unconventional RO system. These include:

1. Pump power and capacity is reduced by $\mathbf{5 2 \%}$ !

2. Outlet pump pressure is cut approximately in half allowing greater efficiency, lower maintenance costs, and lower cost per unit of capacity.

3. The need for an ERD is totally eliminated!

4. An OTEC powered system further reduces power consumption and eliminates the need for and electric power source and electric supply line to the system.

5. The head difference between sea and fresh water provides some of the "pumping power".

6. The system is not subject to tornados, hurricanes, typhoons, and tsunamis.

It is true that deploying an RO system at a depth of around 300 meters is more complicated than land based RO and additional piping is required. The technology required is already well understood from the offshore oil and gas industry. The reduction in capacity and supply pressure of the system and elimination of ERD will provide much of the added cost of deploying the system in the ocean at a distance from shore. The energy savings will provide a quick payback period for the investment. In order for this technology to move ahead, a sound economic analysis is required to quantify the economics and risk to provide investors with the incentive to incorporate the proposed system.

\section{References}

[1] Vega L.A. (1995), “Ocean Thermal Energy Conversion”, Encyclopedia of Energy Technology and the Environment, John Wiley \& Sons, Inc., New York, NY, pp. 2104-2119.

[2] Howard, R.J., et al. US Patent 8117843, 2012.

[3] Berger LR, Berger JA (June 1986). "Countermeasures to Microbiofouling in Simulated Ocean Thermal Energy Conversion Heat Exchangers with Surface and Deep Ocean Waters in Hawaii”. Appl. Environ. Microbiol. 51 (6): 1186-1198.

[4] Ocean thermal energy conversion, http://en.wikipedia.org/wiki/ Ocean thermal_energy_conversion, 2012.

[5] Desalination; http://en.wikipedia.org/wiki/Desalination

[6] Lee, K. P., Arnot, T. C. and Mattia, D., 2011. "A review of reverse osmosis membrane materials for desalination-Development to date and future potential". Journal of Membrane Science, 370 (1-2), pp. 1-22.

[7] Elimelech, M., Phillip, W.A., "The Future of Seawater Desalination: Energy, Technology, and the Environment Science"; Science 5 August 2011: Vol. 333 no. 6043 pp. 712-717. 
[8] Sun JiaXi; Wang Yue; Xu ShiChang; Wang ShiChang; Wang YuXin; Performance prediction of hydraulic energy recovery (HER) device with novel mechanics for small-scale SWRO desalination system. Desalination 2009 Vol. 249 No. 2 pp. 667-671.

[9] MacHarg, J., Seacord, T., Sessions, B., "ADC Baseline Tests Reveal Trends in Membrane Performance", Desalination and Water Reuse, Vol. 18/2, 2008.

[10] "Affordable Desalination Profiles State of the Art SWRO", www.affordabledesal.com, March 27, 2008.

[11] MacHarg, J., and Truby, R., "West Coast Researchers Seek to Demonstrate SWRO Affordability", Desalination and Water Reuse, Vol. 14/3, 2006. 